\title{
Prevalent Synergy and Antagonism Among Antibiotics and Biocides in Pseudomonas aeruginosa
}

\section{OPEN ACCESS}

Edited by:

Fabian Cieplik,

University Medical Center

Regensburg, Germany

Reviewed by:

Karl-Anton Hiller,

University Medical Center

Regensburg, Germany

Agata Woźniak,

Intercollegiate Faculty of

Biotechnology of University of Gdańsk and Medical University of

Gdańsk, Poland

Mark Willcox,

University of New South Wales,

Australia

*Correspondence: Frank Schreiber

frank.schreiber@bam.de

Specialty section:

This article was submitted to Antimicrobials, Resistance and

Chemotherapy,

a section of the journal

Frontiers in Microbiology

Received: 09 October 2020 Accepted: 15 December 2020

Published: 04 February 2021

Citation:

Pietsch F, Heidrich G, Nordholt N and Schreiber F (2021) Prevalent Synergy and Antagonism Among Antibiotics and Biocides in Pseudomonas aeruginosa.

Front. Microbiol. 11:615618. doi: 10.3389/fmicb.2020.615618

\author{
Franziska Pietsch, Gabriele Heidrich, Niclas Nordholt and Frank Schreiber*
}

Division of Biodeterioration and Reference Organisms (4.1), Department of Materials and the Environment, Federal Institute for Materials Research and Testing (BAM), Berlin, Germany

Antimicrobials can exert specific physiological effects when used in combination that are different from those when applied alone. While combination effects have been extensively mapped for antibiotic-antibiotic combinations, the combination effects of antibiotics with antimicrobials used as biocides or antiseptics have not been systematically investigated. Here, we investigated the effects of combinations of antibiotics (meropenem, gentamicin, and ciprofloxacin) and substances used as biocides or antiseptics [octenidine, benzalkonium chloride, cetrimonium bromide, chlorhexidine, Povidone-iodine, silver nitrate $\left(\mathrm{AgNO}_{3}\right)$, and Ag-nanoparticles] on the planktonic growth rate of Pseudomonas aeruginosa. Combination effects were investigated in growth experiments in microtiter plates at different concentrations and the Bliss interaction scores were calculated. Among the 21 screened combinations, we find prevalent combination effects with synergy occurring six times and antagonism occurring 10 times. The effects are specific to the antibiotic-biocide combination with meropenem showing a tendency for antagonism with biocides (6 of 7 ), while gentamicin has a tendency for synergy (5 of 7 ). In conclusion, antibiotics and biocides or antiseptics exert physiological combination effects on the pathogen $P$. aeruginosa. These effects have consequences for the efficacy of both types of substances and potentially for the selection of antimicrobial resistant strains in clinical applications with combined exposure (e.g., wound care and coated biomaterials).

Keywords: synergy, antagonism, suppression, biocides, antibiotics, pseudomonas aeruginosa, CTAB (cetyltrimethylammonium bromide), Povidone-iodine (PVP-I)

\section{INTRODUCTION}

Combinatorial exposure to multiple antibiotics has been suggested to improve treatment outcome, especially for infections with multi-drug resistant bacteria (Tamma et al., 2012; Tyers and Wright, 2019). However, depending on the conditions, combination treatment may accelerate or delay resistance selection (Hegreness et al., 2008; Michel et al., 2008; Baym et al., 2015; Barbosa et al., 2018). Therefore, choosing the best combination requires knowledge on possible physiological interactions between the effects of the combined active substances; i.e., are their individual effects simply added, potentiated (synergy), or buffered (antagonism and supression) when used in combination (Baym et al., 2015). 
Combinatorial effects among antibiotics (Yeh et al., 2006; Brochado et al., 2018), antimicrobial peptides (Yu et al., 2016), and antibiotics with virulence factors (Rezzoagli et al., 2020) have been mapped extensively. In contrast, combinatorial effects of compounds used as disinfectants, preservatives, antiseptics, and as antimicrobial surface coatings (for simplicity from now on called biocides) with antibiotics received less attention (Brochado et al., 2018). However, there are several situations in which antibiotics and biocides can exert combination effects on microbes. These situations are related to clinical treatment schemes in which topical treatment of microbial infections with antiseptics is supported by systemic antibiotic dosing; for example, treatment of chronic wounds (Sibbald et al., 2007; Leaper et al., 2012) and implantation of medical devices coated with antimicrobials (von Eiff et al., 2005; Busscher et al., 2012; Moriarty et al., 2013). In addition, microbes might be exposed to combinations of antibiotics and biocides in certain environmental compartments such as hospital wastewater or wastewater treatment plants.

Here, we investigate combinatorial effects of antibiotics and biocides on the pathogen Pseudomonas aeruginosa. We chose $P$. aeruginosa because it is a prevalent pathogen in clinical situations in which antibiotics and antiseptics or biocides meet; i.e., it often occurs in wound infections (Percival et al., 2015; Serra et al., 2015), it is known to colonize medical implants (Percival et al., 2015), and it is known to be widespread in environmental compartments. We chose three antibiotics that are used to treat $P$. aeruginosa infections and seven biocides, all covering a range of classes, modes of action and applications (Table 1).

\section{MATERIALS AND METHODS}

\section{Strains and Growth Conditions}

The experiments were performed with $P$. aeruginosa MPAO1 obtained from Colin Manoil (Jacobs et al., 2003; Varadarajan et al., 2020). The ancestor strain was isolated from a wound in Melbourne, Australia, in 1954 (Holloway, 1955; Chandler et al., 2019). All assays were conducted in $200 \mu$ l volume in a polypropylene (PP; PP has lower binding for positively charged biocides as compared to polystyrene) 96-well microtiter plate incubated at $37^{\circ} \mathrm{C}$ with shaking (fast, orbital mode) in a plate reader $\left(\mathrm{EPOCH} 2\right.$, Biotek) with readings for $\mathrm{OD}_{600}$ obtained in a $5 \mathrm{~min}$ interval. The inoculum was $10^{5}$ cells per $\mathrm{ml}$ and consisted of a pre-culture of exponential cells in M9 $[5 \times \mathrm{M} 9$ minimal salts base from Formedium (final concentrations: $6.78 \mathrm{~g} \mathrm{~L}^{-1} \mathrm{Na}_{2} \mathrm{HPO}_{4} ; 3 \mathrm{~g} \mathrm{~L}^{-1} \mathrm{KH}_{2} \mathrm{PO}_{4} ; 0.5 \mathrm{~g} \mathrm{~L}^{-1}$ $\mathrm{NaCl} ; 1 \mathrm{~g} \mathrm{~L}^{-1} \mathrm{NH}_{4} \mathrm{Cl}$ ) supplemented with $2 \mathrm{mM} \mathrm{MgSO}_{4}$, $100 \mu \mathrm{M} \mathrm{CaCl} 2,20 \mathrm{mM}$ glucose, $25 \mu \mathrm{M} \mathrm{FeCl}_{3} \cdot 6 \mathrm{H}_{2} \mathrm{O}, 4.95 \mu \mathrm{M}$ $\mathrm{ZnCl}_{2}, 2.1 \mu \mathrm{M} \mathrm{CoCl} \cdot 6 \mathrm{H}_{2} \mathrm{O}, 2 \mu \mathrm{M} \mathrm{Na} \mathrm{MoO}_{4} \cdot 2 \mathrm{H}_{2} \mathrm{O}, 1.7 \mu \mathrm{M}$ $\mathrm{CaCl}_{2} \cdot 2 \mathrm{H}_{2} \mathrm{O}, 2.5 \mu \mathrm{M} \mathrm{CuCl} \cdot 2 \mathrm{H}_{2} \mathrm{O}, 2 \mu \mathrm{M} \mathrm{H}_{3} \mathrm{BO}_{3}$ ] that were stored at $-80^{\circ} \mathrm{C}$ until use (each freezer stock was only thawed once). Defined M9 medium was chosen for the experiments instead of nutritionally-rich media such as Mueller-Hinton broth (recommended for standard antimicrobial susceptibly testing) to generate data that can be reproduced despite apparent differences between different Mueller-Hinton brands (Ahman et al., 2020), to minimize interactions between medium and biocides, and to allow tracing of the molecular mechanism relative to general metabolism in a balanced medium with a single carbon and nitrogen source.

TABLE 1 | Characteristics of antibiotics and biocides screened for interaction effects.

\begin{tabular}{|c|c|c|c|c|c|}
\hline Antibiotic & Class & Mode of action & Application & ${ }^{*} \mathbf{M I C}$ & ${ }^{*, \# E C 50}$ \\
\hline Meropenem & $\begin{array}{l}\text { Carbapenem; beta- } \\
\text { lactam }\end{array}$ & Inhibition of bacterial cell wall synthesis & $\begin{array}{l}\text { Broad spectrum; treatment of } \\
\text { infections with MDR bacteria }\end{array}$ & 0.075 & $0.061(0.004)$ \\
\hline Ciprofloxacin & Fluoroquinolone & Inhibition of DNA transcription and replication & Broad spectrum & 1.5 & $0.22(0.39)$ \\
\hline Gentamicin & Aminoglycoside & Inhibition of protein synthesis & Broad spectrum; topical applications & 0.5 & $0.30(0.07)$ \\
\hline \multicolumn{6}{|l|}{ Biocide } \\
\hline Octenidine & Cationic surfactant & $\begin{array}{l}\text { Binds to cell envelope; Interaction with } \\
\text { enzymes and polysaccharides in the cell } \\
\text { envelope; induces leakage in the cytoplasmic } \\
\text { membrane }\end{array}$ & $\begin{array}{l}\text { Antiseptic for skin disinfection and } \\
\text { wound treatment }\end{array}$ & 1 & $0.8(0.3)$ \\
\hline $\begin{array}{l}\text { Benzalkonium chloride } \\
\text { (BAC) }\end{array}$ & $\begin{array}{l}\text { Cationic quaternary } \\
\text { ammonium compound }\end{array}$ & $\begin{array}{l}\text { Interacts with cell membranes, leading to } \\
\text { disruption of membrane integrity and leakage } \\
\text { of cellular content }\end{array}$ & $\begin{array}{l}\text { Antiseptic ointments, drops, creams } \\
\text { and sprays; antimicrobial coatings }\end{array}$ & 25 & $21.4(0.8)$ \\
\hline $\begin{array}{l}\text { Cetrimonium bromide } \\
\text { (CTAB) }\end{array}$ & $\begin{array}{l}\text { Cationic quaternary } \\
\text { ammonium compound }\end{array}$ & $\begin{array}{l}\text { Binding to lipid components of the cell } \\
\text { membrane, causing membrane rupture and } \\
\text { cell lysis }\end{array}$ & $\begin{array}{l}\text { Antimicrobial coating and topical } \\
\text { antiseptic in hygiene and } \\
\text { pharmaceuticals }\end{array}$ & 16 & $13.3(0.8)$ \\
\hline Chlorhexidine & Cationic biguanide & $\begin{array}{l}\text { Binds to negatively charged bacterial walls, } \\
\text { causing membrane disruption and leakage }\end{array}$ & $\begin{array}{l}\text { Topical skin disinfectants, wound and } \\
\text { burn dressings, coating of catheters }\end{array}$ & 7.6 & $5.6(0.2)$ \\
\hline $\begin{array}{l}\text { Povidone-iodine } \\
\text { (PVP-I) }\end{array}$ & Halogen & $\begin{array}{l}\text { Rapidly penetrates microorganisms, damaging } \\
\text { proteins, nucleotides and fatty acids }\end{array}$ & Disinfectant in wound dressings & 150 & $138(5)$ \\
\hline Silver nitrate $\left(\mathrm{AgNO}_{3}\right)$ & Transition metal & $\begin{array}{l}\text { Ability to bind FeS-clusters or thiol-groups of } \\
\text { enzymes, inhibiting cellular functions such as } \\
\text { electron transport chain; ROS formation }\end{array}$ & $\begin{array}{l}\text { Topical antiseptic on moist skin, } \\
\text { mucous and skin wounds }\end{array}$ & 0.01 & $0.0058(0.0006)$ \\
\hline $\begin{array}{l}\text { Silver nanoparticles } \\
\text { (AgNP) }\end{array}$ & Transition metal & Similar to $\mathrm{AgNO}_{3}$ & $\begin{array}{l}\text { Antimicrobial coating on medical } \\
\text { devices }\end{array}$ & 0.03 & $0.026(6.8)$ \\
\hline
\end{tabular}

${ }^{*} \mathrm{MIC}$ and $\mathrm{EC}_{50}$ measured in M9 medium, concentration in $\mu \mathrm{g} \mathrm{ml}^{-1}$.

"The brackets depict the standard error of the simultaneous dose-response fit of three biological replicates scaled with the square route of the reduced $\chi^{2}$. 


\section{Determination of $\mathrm{MIC}$ and $\mathrm{EC}_{50}$}

Minimum inhibitory concentrations (MIC) were determined by broth microdilution according to the standard method described previously (Wiegand et al., 2008) with the following modifications: M9 was used as growth medium, microtiter plates were incubated under shaking conditions, and pre-cultures were used from exponential cultures that were stored at $-80^{\circ} \mathrm{C}$ and thawed on ice prior to the experiment. Wells were inoculated with $5 \times 10^{3} \mathrm{CFU}$ per well containing $200 \mu \mathrm{l}$ medium. $\mathrm{OD}_{600}$ values were recorded in a microplate reader (BioTek EPOCH 2, intermediate linear shaking, $37^{\circ} \mathrm{C}$ ) every $5 \mathrm{~min}$ for $24 \mathrm{~h}$. All measurements were run at least in triplicate. The lowest concentration for which no growth was observed in all replicates based on $\mathrm{OD}_{600}$ after $24 \mathrm{~h}$ was set as MIC. Wells containing only M9 and the specific antimicrobial substance without cells served as background control. In parallel, half-maximal effective concentrations $\left(\mathrm{EC}_{50}\right)$ were derived from maximum growth rates at different antimicrobial concentrations. The growth rate was calculated from the increase in $\mathrm{OD}_{600}$ over time by inferring the time derivative using Gaussian processes implemented as published code (Swain et al., 2016) in Python 3.6 and fitting a dose-response model to the data of the combined three biological replicates (DoseResp fit, Origin 2019 v9.6, OriginLab).

\section{Combination Effects}

A three-step procedure was used to identify physiological interactions of antibiotics and biocides. First, we determined the minimal inhibitory concentrations $\mathrm{MICs}$ and $\mathrm{EC}_{50}$ of all compounds in isolation (see section above, Table 1). Secondly, for each antibiotic-biocide combination, we determined the growth rates of seven biological replicate cell populations in M9 minimal medium (i) without antimicrobials, (ii) with the antibiotic alone at approximately the $\mathrm{EC}_{50}$, (iii) with five concentrations close to the $\mathrm{EC}_{50}$ of the biocide alone (see Supplementary Table S1), and (iv) with five combinations of the antibiotic at approximately $\mathrm{EC}_{50}$ supplied simultaneously with the biocide at five concentrations close to the $\mathrm{EC}_{50}$ (exactly those as measured in the "biocide alone" treatment). Each antibiotic-biocide combination was tested in parallel on the same day to minimize day-to-day variations in growth rate effects of antibiotics, which emerged due to steep dose-response curves and which were especially apparent for meropenem (Figure 1). Thirdly, we calculated the interaction effects of the combinations based on the Bliss independence model (Bliss, 1939).

\section{Calculations and Statistics}

The Bliss independence model was chosen because it is recommended for compounds that affect different target sites (Baeder et al., 2016) as expected for antibiotics and biocides. An alternative model is Loewe additivity including the popular checkerboard assay with calculation of the factorial inhibition concentration index (Loewe, 1953; Hallander et al., 1982). It has been shown that Bliss independence (response additivity) and Loewe (dosage

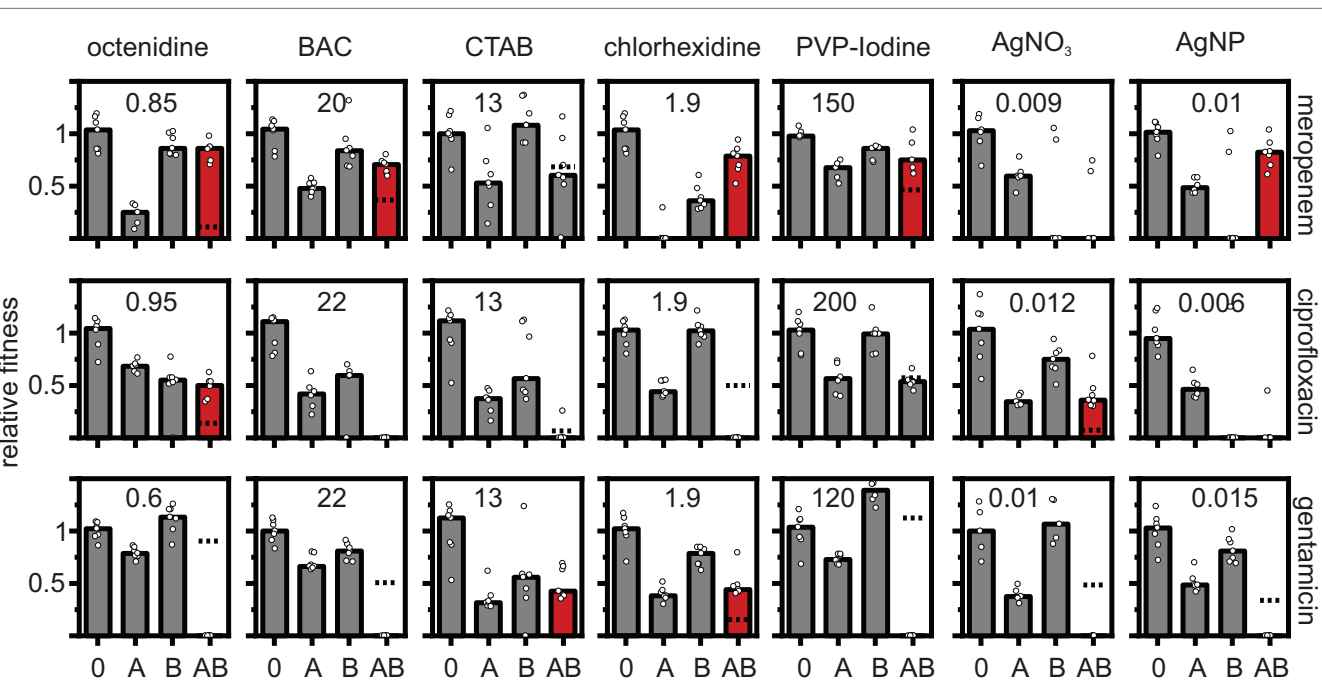

FIGURE 1 | Effects of antibiotic-biocide combinations on the relative fitness of Pseudomonas aeruginosa MPAO1. Relative fitness was measured as the growth rate in the absence of antimicrobial (0), in the presence of antibiotic (A), in the presence of biocide (B), and in the presence of a combination of antibiotic with biocide (AB) normalized by the growth rate in the absence of antimicrobial. Concentrations of antibiotics were $0.06 \mu \mathrm{g} \mathrm{ml}{ }^{-1}$ for meropenem; $0.6 \mu \mathrm{g} \mathrm{ml}{ }^{-1}$ for ciprofloxacin; and $0.18 \mu \mathrm{g} \mathrm{ml}^{-1}$ for gentamicin. The concentrations of the biocides (in $\mu \mathrm{g} \mathrm{ml}^{-1}$ ) are depicted in each panel. The dashed lines depict the combined effect of both antibiotic and biocide predicted under the Bliss independence model. The predicted fitness under combinatorial treatment is zero in panels in which the dashed line is absent. Combinations that show a higher measured fitness in the presence of the combination as compared to the predicted fitness are typically antagonistic (shown as red bars). Combinations that show a lower measured fitness in the presence of the combination as compared to the predicted fitness are synergistic (dashed line displayed, but measured fitness in combination typically equals zero). Additive combinations are shown as gray bars. Significance was tested with a one-sample $t$-test on the Bliss interaction score as described in the main text (see Figure 2). The bars represent the median and the white circles represent individual measurements of seven biological replicates (in some treatments one or two replicates had to be omitted due to difficulties in fitting the growth curves). 
additivity) give robust results when calculating effects of pairwise combinations of a large array of antibiotics (Russ and Kishony, 2018). The Bliss interaction score (S) was defined as the difference between the measured combined effect $\left(\mathrm{E}_{\mathrm{AB}}\right)$ and the summed, single effects of the antibiotics $\left(\mathrm{E}_{\mathrm{A}}\right)$ and the biocides $\left(\mathrm{E}_{\mathrm{B}}\right) ; \mathrm{S}=\mathrm{E}_{\mathrm{AB}}-\left(\mathrm{E}_{\mathrm{A}}+\mathrm{E}_{\mathrm{B}}\right)$ (Russ and Kishony, 2018). An additive definition of the Bliss model was used because the effects were based on growth rates rather than yield measurements (Baeder et al., 2016; Russ and Kishony, 2018). All effects of antimicrobials or their combinations $\left(\mathrm{E}_{\mathrm{i}}\right)$ were calculated as the difference between the measured growth rate without antimicrobial $\left(\mathrm{g}_{0}\right)$ and the growth rates with antimicrobials $\left(\mathrm{g}_{\mathrm{i}}\right)$, relative to the growth rate without antimicrobial; $\mathrm{E}_{\mathrm{i}}=\left(\mathrm{g}_{0}-\mathrm{g}_{\mathrm{i}}\right) / \mathrm{g}_{0}$ (Russ and Kishony, 2018). Bliss interactions scores of each antibioticbiocide combination were calculated for each of the seven biological replicates separately and tested for normality with a Kolmogorov-Smirnov test (normality was not rejected for any biocide-antibiotic combination at $p<0.05$, Origin 2019 v9.6). Next, the Bliss interactions scores of each antibioticbiocide combination were tested for a significant deviation from zero (additive combination effect) with a one-sample $t$-test (Origin 2019 v9.6, OriginLab, at $\mathrm{p}<0.05$ ).

\section{RESULTS AND DISCUSSION}

The results show prevalent combination effects when antibiotics and biocides were applied simultaneously with synergy occurring six times and antagonism occurring 10 times among the 21 screened combinations (Figures 1, 2). The effects are specific to the antibiotic-biocide combination, with some apparent patterns. Interactions of biocides with meropenem were predominantly antagonistic (6 of 7 , except for cetrimonium bromide (CTAB), which showed no significant interaction), while interactions of biocides with gentamicin were predominately synergistic (5 of 7 , except for CTAB and chlorhexidine, which both were antagonistic). For ciprofloxacin, we detected three significant interactions; octenidine, silver nitrate $\left(\mathrm{AgNO}_{3}\right.$; antagonism), and chlorhexidine (synergy).

Biocides with similar chemistries mostly showed consistent interactions with different antibiotics. For example, cationic surfactants (octenidine) and cationic quaternary ammonium compounds [QACs, here benzalkonium chloride (BAC)] were antagonistic with meropenem and synergistic with gentamicin. However, CTAB, which is also a cationic QAC, did not show an interaction with meropenem and was antagonistic with gentamicin. Moreover, $\mathrm{AgNO}_{3}$ and silver nanoparticles (AgNP) were antagonistic with meropenem and synergistic with gentamicin. The observed interactions between antibiotics and silver are consistent with previous reports that showed synergistic effects between aminoglycosides and silver on killing of planktonic Escherichia coli (Morones-Ramirez et al., 2013) and biofilms of P. aeruginosa (Habash et al., 2017), and that showed no effect on planktonic growth of $P$. aeruginosa ATCC 10145 for the ciprofloxacin-AgNP combination (Markowska et al., 2014). In contrast, the antagonistic effect between AgNP and meropenem apparent in our data has not been observed previously in P. aeruginosa ATCC 10145 (Markowska et al., 2014). In addition, a strain-specific, synergistic effect between chlorhexidine and gentamicin for clinical isolates of $P$. aeruginosa has been described previously (Barnham and Kerby, 1980), while our data show antagonistic effects on strain MPAO1.

Here, we present the first comprehensive screen of physiological interactions of antibiotic-biocide combinations in $P$. aeruginosa. This data will provide the basis for designing improved treatment protocols in which biocides/antiseptics and antibiotics are used in combination. This might be particularly important in situations in which these antimicrobials establish concentration gradients. Such gradients may lead to the establishment of relevant combinatorial concentrations that then might lead to combination effects on growth. The results provide the basis for future work that should focus on (i) confirming the combination effects with other established concepts such as Loewe additivity (including

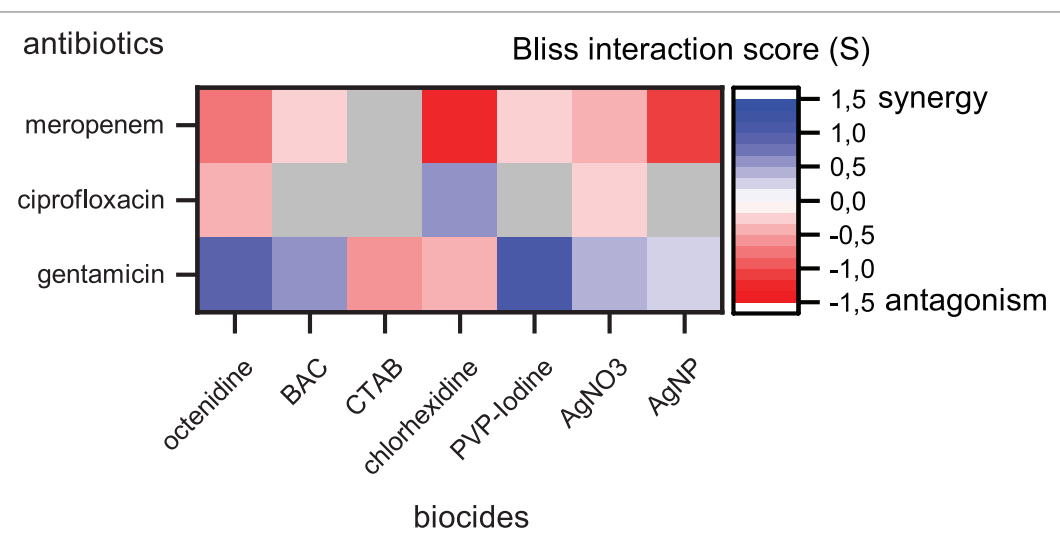

FIGURE 2 | Synergy and antagonism between antibiotics and biocides based on Bliss interaction scores. Red colors depict antagonistic and blue colors depict synergistic interactions. Combinations displayed in colors were significant according to a one-sample $t$-test $(p<0.05)$. Combinations displayed in gray were not significant. Note that our assay cannot fully exclude synergy or antagonism for those combinations shown in gray. These interactions might be detectable if more combinations of different concentrations are tested. 
the factorial inhibition concentration; Hallander et al., 1982), (ii) expand the screen for combination effects to other antibiotics (e.g., antimicrobial peptides) and antiseptics/biocides, (iii) mapping the occurrence of the combination effects across $P$. aeruginosa clinical isolates and other pathogens, and (iv) investigating the molecular mechanism behind the combination effects by gene expression or knockout studies. Moreover, future research should explore potential evolutionary consequences of the physiological interaction effects between antibiotics and biocides. This is relevant because the nature of the physiological interaction (synergy or antagonism) has been shown to underpin selection for or against antimicrobial resistant strains in competition with sensitive strains exposed to combinations of antimicrobials (Chait et al., 2007, 2016; Baym et al., 2015; Rezzoagli et al., 2020).

\section{DATA AVAILABILITY STATEMENT}

The raw data supporting the conclusions of this article will be made available by the authors, without undue reservation.

\section{REFERENCES}

Ahman, J., Matuschek, E., and Kahlmeter, G. (2020). EUCAST evaluation of 21 brands of Mueller-Hinton dehydrated media for disc diffusion testing. Clin. Microbiol. Infect. 26, 1412.e1411-1412.e1415. doi: 10.1016/j. cmi.2020.01.018

Baeder, D. Y., Yu, G., Hozé, N., Rolff, J., and Regoes, R. R. (2016). Antimicrobial combinations: Bliss independence and Loewe additivity derived from mechanistic multi-hit models. Philos. Trans. R. Soc. Lond. Ser. B Biol. Sci. 371:20150294. doi: 10.1098/rstb.2015.0294

Barbosa, C., Beardmore, R., Schulenburg, H., and Jansen, G. (2018). Antibiotic combination efficacy (ACE) networks for a Pseudomonas aeruginosa model. PLoS Biol. 16:e2004356. doi: 10.1371/journal.pbio.2004356

Barnham, M., and Kerby, J. (1980). Antibacterial activity of combinations of chlorhexidine with neomycin and gentamicin. J. Hosp. Infect. 1, 77-81. doi: 10.1016/0195-6701(80)90034-1

Baym, M., Stone, L. K., and Kishony, R. (2015). Multidrug evolutionary strategies to reverse antibiotic resistance. Science 351:aad3292. doi: 10.1126/science. aad 3292

Bliss, C. I. (1939). The toxicity of poisons applied jointly. Ann. Appl. Biol. 26, 585-615. doi: 10.1111/j.1744-7348.1939.tb06990.x

Brochado, A. R., Telzerow, A., Bobonis, J., Banzhaf, M., Mateus, A., Selkrig, J., et al. (2018). Species-specific activity of antibacterial drug combinations. Nature 559, 259-263. doi: 10.1038/s41586-018-0278-9

Busscher, H. J., Mei, H. C. V. D., Subbiahdoss, G., Jutte, P. C., van den Dungen, J. J. A. M., Zaat, S. A. J., et al. (2012). Biomaterial-associated infection: locating the finish line in the race for the surface. Sci. Transl. Med. 4:153rv110. doi: $10.1126 /$ scitranslmed.3004528

Chait, R., Craney, A., and Kishony, R. (2007). Antibiotic interactions that select against resistance. Nature 446, 668-671. doi: 10.1038/nature05685

Chait, R., Palmer, A. C., Yelin, I., and Kishony, R. (2016). Pervasive selection for and against antibiotic resistance in inhomogeneous multistress environments. Nat. Commun. 7:10333. doi: 10.1038/ncomms10333

Chandler, C. E., Horspool, A. M., Hill, P. J., Wozniak, D. J., Schertzer, J. W., Rasko, D. A., et al. (2019). Genomic and phenotypic diversity among ten laboratory isolates of Pseudomonas aeruginosa PAO1. J. Bacteriol. 201, e00595-e00618. doi: 10.1128/JB.00595-18

Habash, M. B., Goodyear, M. C., Park, A. J., Surette, M. D., Vis, E. C., Harris, R. J., et al. (2017). Potentiation of tobramycin by silver nanoparticles against Pseudomonas aeruginosa biofilms. Antimicrob. Agents Chemother. 61, e00415-e00417. doi: 10.1128/AAC.00415-17

\section{AUTHOR CONTRIBUTIONS}

FS conceived the study. FP and FS designed the experiments. FP and GH performed the experiments. FP, GH, NN, and FS analyzed the data. FS wrote the manuscript with input from all co-authors. All authors contributed to the article and approved the submitted version.

\section{FUNDING}

This work was funded by a grant of the Joint Programming Initiative on Antimicrobial Resistance (JPI-EC-AMR); BEAT-AMR project funded by BMBF (\#01KI1710) and by BAM.

\section{SUPPLEMENTARY MATERIAL}

The Supplementary Material for this article can be found online at: https://www.frontiersin.org/articles/10.3389/fmicb.2020.615618/ full\#supplementary-material

Hallander, H. O., Dornbusch, K., Gezelius, L., Jacobson, K., and Karlsson, I. (1982). Synergism between aminoglycosides and cephalosporins with antipseudomonal activity: interaction index and killing curve method. Antimicrob. Agents Chemother. 22, 743-752. doi: 10.1128/aac.22.5.743

Hegreness, M., Shoresh, N., Damian, D., Hartl, D., and Kishony, R. (2008). Accelerated evolution of resistance in multidrug environments. Proc. Natl. Acad. Sci. U. S. A. 105, 13977-13981. doi: 10.1073/pnas.0805965105

Holloway, B. W. (1955). Genetic recombination in Pseudomonas aeruginosa. Microbiology 13, 572-581. doi: 10.1099/00221287-13-3-572

Jacobs, M. A., Alwood, A., Thaipisuttikul, I., Spencer, D., Haugen, E., Ernst, S., et al. (2003). Comprehensive transposon mutant library of Pseudomonas aeruginosa. Proc. Natl. Acad. Sci. U. S. A. 100, 14339-14344. doi: 10.1073/ pnas. 2036282100

Leaper, D. J., Schultz, G., Carville, K., Fletcher, J., Swanson, T., and Drake, R. (2012). Extending the TIME concept: what have we learned in the past 10 years? $\left(^{*}\right)$. Int. Wound J. 9 (Suppl. 2), 1-19. doi: 10.1111/j.1742-481X.2012.01097.x

Loewe, S. (1953). The problem of synergism and antagonism of combined drugs. Arzneimittelforschung 3, 285-290.

Markowska, K., Grudniak, A. M., Krawczyk, K., Wrobel, I., and Wolska, K. I. (2014). Modulation of antibiotic resistance and induction of a stress response in Pseudomonas aeruginosa by silver nanoparticles. J. Med. Microbiol. 63, 849-854. doi: 10.1099/jmm.0.068833-0

Michel, J. -B., Yeh, P. J., Chait, R., Moellering, R. C., and Kishony, R. (2008). Drug interactions modulate the potential for evolution of resistance. Proc Natl. Acad. Sci. U. S. A. 105, 14918-14923. doi: 10.1073/pnas.0800944105

Moriarty, T. F., Zaat, S. A. J., and Busscher, H. J. (2013). Biomaterials associated infection. New York, NY: Springer.

Morones-Ramirez, J. R., Winkler, J. A., Spina, C. S., and Collins, J. J. (2013). Silver enhances antibiotic activity against Gram-negative bacteria. Sci. Transl. Med. 5:190ra181. doi: 10.1126/scitranslmed.3006276

Percival, S. L., Suleman, L., Vuotto, C., and Donelli, G. (2015). Healthcareassociated infections, medical devices and biofilms: risk, tolerance and control. J. Med. Microbiol. 64, 323-334. doi: 10.1099/jmm.0.000032

Rezzoagli, C., Archetti, M., Mignot, I., Baumgartner, M., and Kümmerli, R. (2020). Combining antibiotics with antivirulence compounds can have synergistic effects and reverse selection for antibiotic resistance in Pseudomonas aeruginosa. PLoS Biol. 18:e3000805. doi: 10.1371/journal.pbio.3000805

Russ, D., and Kishony, R. (2018). Additivity of inhibitory effects in multidrug combinations. Nat. Microbiol. 3, 1339-1345. doi: 10.1038/s41564-018-0252-1

Serra, R., Grande, R., Butrico, L., Rossi, A., Settimio, U. F., Caroleo, B., et al. (2015). Chronic wound infections: the role of Pseudomonas aeruginosa and 
Staphylococcus aureus. Expert Rev. Anti-Infect. Ther. 13, 605-613. doi: 10.1586/ 14787210.2015.1023291

Sibbald, R. G., Woo, K., and Ayello, E. (2007). Increased bacterial burden and infection: the story of NERDS and STONES. Adv. Skin. Wound Care 19, 447-461. doi: 10.1097/00129334-200610000-00012

Swain, P. S., Stevenson, K., Leary, A., Montano-Gutierrez, L. F., Clark, I. B. N., Vogel, J., et al. (2016). Inferring time derivatives including cell growth rates using Gaussian processes. Nat. Commun. 7:13766. doi: 10.1038/ncomms13766

Tamma, P. D., Cosgrove, S. E., and Maragakis, L. L. (2012). Combination therapy for treatment of infections with gram-negative bacteria. Clin. Microbiol. Rev. 25, 450-470. doi: 10.1128/CMR.05041-11

Tyers, M., and Wright, G. D. (2019). Drug combinations: a strategy to extend the life of antibiotics in the 21st century. Nat. Rev. Microbiol. 17, 141-155. doi: 10.1038/s41579-018-0141-x

Varadarajan, A. R., Allan, R. N., Valentin, J. D. P., Castañeda Ocampo, O. E., Somerville, V., Pietsch, F, et al. (2020). An integrated model system to gain mechanistic insights into biofilm-associated antimicrobial resistance in Pseudomonas aeruginosa MPAO1. NPJ Biofilms Microbiomes 6:46. doi: 10.1038/ s41522-020-00154-8

von Eiff, C., Jansen, B., Kohnen, W., and Becker, K. (2005). Infections associated with medical devices. Drugs 65, 179-214. doi: 10.2165/00003495-200565020-00003
Wiegand, I., Hilpert, K., and Hancock, R. E. W. (2008). Agar and broth dilution methods to determine the minimal inhibitory concentration (MIC) of antimicrobial substances. Nat. Protoc. 3, 163-175. doi: 10.1038/nprot.2007.521

Yeh, P., Tschumi, A. I., and Kishony, R. (2006). Functional classification of drugs by properties of their pairwise interactions. Nat. Genet. 38, 489-494. doi: $10.1038 /$ ng 1755

Yu, G., Baeder, D. Y., Regoes, R. R., and Rolff, J. (2016). Combination effects of antimicrobial peptides. Antimicrob. Agents Chemother. 60, 1717-1724. doi: 10.1128/AAC.02434-15

Conflict of Interest: The authors declare that the research was conducted in the absence of any commercial or financial relationships that could be construed as a potential conflict of interest.

Copyright (c) 2021 Pietsch, Heidrich, Nordholt and Schreiber. This is an open-access article distributed under the terms of the Creative Commons Attribution License (CC BY). The use, distribution or reproduction in other forums is permitted, provided the original author(s) and the copyright owner(s) are credited and that the original publication in this journal is cited, in accordance with accepted academic practice. No use, distribution or reproduction is permitted which does not comply with these terms. 